\title{
Explosive oil prices
}

\author{
Marc Gronwald* \\ September 2016
}

\begin{abstract}
Spectacular oil price increases occur on a regular basis; the most recent one is dated July 2008. This paper puts forward the notion that extreme oil price movements of this type can be described as temporary explosive. The paper applies a forward recursive unit root tests and finds evidence of explosive behavior in the following periods: 1990/1991, 2005/2006, and 2007/2008. Currently existing oil price models are not capable of appropriately describing this type of behavior. A thorough discussion of the underlying reasons of these price hikes indicates these oil price episodes - even though extreme are mainly fundamentally explained. This finding is insufficiently acknowledged in the literature on speculative oil price bubbles. Thus, policy interventions as response to extreme movements of this kind need to be very carefully thought through.
\end{abstract}

Keywords: Oil prices, Explosiveness, Fundamentals, Bubble, Speculation

JEL-Classification: C12, C58

*University of Aberdeen Business School, Dunbar Street, Aberdeen, AB24 3QY, United Kingdom, phone: 00441224 272204, email: mgronwald@abdn.ac.uk. The author is grateful for the hospitality of the University of California, Berkeley as well as Resources for the Future, Washington, DC, while working on the paper. Financial support by the Fritz Thyssen Foundation for these research visits is gratefully acknowledged. An earlier version of this paper appeared as CESifo Working Paper No 4376. 


\section{INTRODUCTION}

Heavy disruptions of the global oil market occur with considerable regularity. Among the manifold examples are the two oil crises, the OPEC collapse, the oil price hike associated with Gulf War II in 1990/1991 and, finally, the episode in July 2008 when oil prices reached a record level of more than 140 USD per barrel. Every one of these disruptions has led to heated debates in both the public and academic arenas. Considerable effort has been made to understand both the macroeconomics and the behavior of oil prices, and this work is well justified for at least two reasons. First, crude oil is still an important economic input factor and there is a widespread notion that virtually all economic recessions are associated with increases in oil prices. Second, crude oil is a fossil resource, the combustion of which is one of the main drivers of climate change.

Not only these disruptions occurred very frequently, also the behaviour of oil prices changed dramatically various times; see Figure 1. Prior to 1986, oil prices moved essentially horizontally, interrupted only by a few shifts never experienced before: dramatic increases 1973/1974 as well as 1979/1980 and a dramatic collapse 1986. Subsequently, the horizontal movement continued, however with a considerably higher volatility. During the beginning of the 2000s, then, a steady increase began, culminating in the oil price record high observed 2008. More recently, oil prices were remarkably stable at around 100 USD per barrel before 2014 a dramatic collapse occurred. These major changes in oil price behavior is usually referred to as structural break; sudden extreme movements are often called jumps. There are, however, two oil price episodes which do seem to be different: in both 1990/1991 and 2008 the oil price movements can certainly also be described as dramatic. In both cases, however, the observed increase is followed by a subsequent collapse. In addition to this, it took the oil price considerable time to reach its respective peak: in 1990/1991 more than three months, in 2008 even

longer. This behaviour is conceptually different from permanent structural breaks, a mere increase in volatility or the occurrence of individual, isolated jumps. 


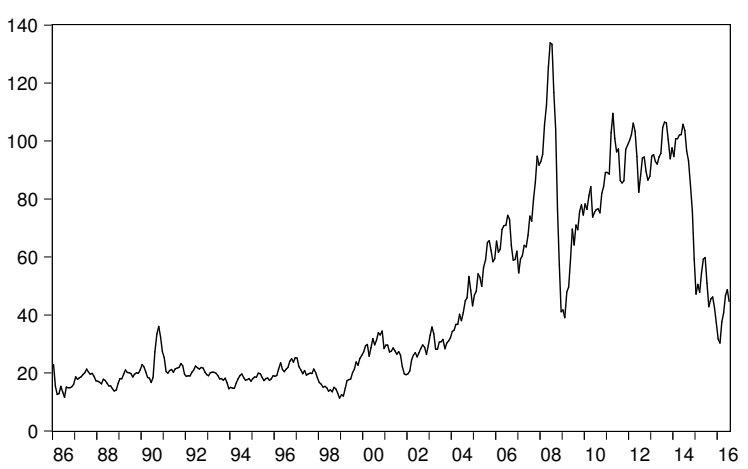

Figure 1: Crude oil prices

This paper empirically examines this type of behavior and employs the concept of temporary explosiveness to capture this behavior. The empirical strategy consists of a forward recursive application of an augmented DickeyFuller unit root test. In each step, the null of a unit root is tested against the alternative of explosiveness. The key result of this exercise is that there is evidence of temporary phases of explosiveness in 1990/1991 as well as in $2005 / 2006$ and $2007 / 2008$. The procedure applied in this paper has been borrowed from Phillips et al. (2011); daily as well as monthly oil price data spanning 1986-2016 are used in the study. ${ }^{1}$ As these steep temporary increases followed by subsequent collapses are conceptually different from from existing oil price descriptions, this empirical finding, standing alone, makes a contribution to the empirical literature on oil price behavior. This literature is epitomized by time series applications such as Lee et al.'s (2006) rather traditional "deterministic vs stochastic trends" paper or Gronwald's (2012) and Lee et al.'s (2010) jump model applications.

A thorough discussion of possible explanations for the identified explosive phases and their relation to the literature on speculative bubbles in oil prices are the second contribution this paper makes. Influential papers such as Kilian and Murphy (2013), Juvenal and Petrella (2014), and and Knittel and Pindyck (2016) show that these oil price surges are mainly explained by

\footnotetext{
${ }^{1}$ Data source: Federal Reserve Bank of St.Louis.
} 
fundamental factors and that speculative activity only plays a minor role. ${ }^{2}$ As the 2004-2008 oil price hike coincided with the so-called financialization of oil futures markets, many believe that this has to be viewed as a driving force behind the hike. Empirical support for this publicly popular claim, however, is practically nonexistent, see Irwin and Sanders (2012) as well as Sanders and Irwin (2014). ${ }^{3}$

To summarize, it is demonstrated that extreme price movements can be captured appropriately by the concept of temporary explosiveness. In addition, these extreme movements can very well have a fundamental explanation: they are a result of the interaction of, first, a change in the relationship between fundamentals of crude oil supply and demand and, second, low price elasticities of oil supply and demand. This is an important message to the general public as it often seems to be believed that extreme price movements can only have non-fundamental causes. However, also a number of academic studies insufficiently acknowledges this finding. Papers including Phillips and Yu (2011), Shi and Arora (2012), and Brooks et al. (2015) deal with speculative bubbles in crude oil prices. The main weakness of these papers, however, are inappropriately modelled fundamental values of oil prices. In addition, the exchange between these strands of literature seems to be overall insufficient. Due to the political dimension of the debate on speculative bubbles particular caution and empirical rigour is essential.

The remainder of the paper is organized as follows. Section 2 outlines the empirical method employed in the paper. Sections 3 and 4 present and discuss the empirical results. Section 5 offers some concluding remarks.

\section{Testing for Explosiveness}

The statistical properties of daily as well as monthly oil prices are investigated here using a forward recursive application of an augmented DickeyFuller unit root test. The null of a unit root is tested against the alternative of an explosive root. Thus, the following equation is estimated:

\footnotetext{
${ }^{2}$ See the original papers for exact defintitions of "speculative activity". Section 4 explains the empirical procedures applied in these papers in more detail.

${ }^{3}$ For an excellent overview of this literature, see Fattouh et al. (2013).
} 


$$
x_{t}=\mu_{x}+\delta x_{t-1}+\sum_{j=1}^{J} \phi_{j} \Delta x_{t-j}+\epsilon_{x, t}, \quad \epsilon_{x, t} \sim \operatorname{NID}\left(0, \sigma_{x}^{2}\right) .
$$

The hypothesis $H_{0}: \delta=1$ is tested against the alternative $H_{1}: \delta>1 .{ }^{4}$ Initially, a subset of the sample with $\tau_{0}=n r_{0}$ observations is used. In each subsequent regression, this subset is supplemented by successive observations, giving a sample of size $\tau=n r$ for $r_{0} \leq r \leq 1$. This procedure yields a sequence of $t$-statistics with corresponding p-values. These sequences are used to identify origination $\hat{r}_{e}$ and collapse dates $\hat{r}_{f}$ of explosive behavior in the data:

$$
\begin{aligned}
& \hat{r}_{e}=\inf _{s \geq r_{0}}\left\{s: \operatorname{ADF}_{s}>\operatorname{cv}_{\beta_{n}}^{\operatorname{adf}}(s)\right\} \\
& \hat{r}_{f}=\inf _{s \geq \hat{r}_{e}}\left\{s: \operatorname{ADF}_{s}<\operatorname{cv}_{\beta_{n}}^{\operatorname{adf}_{n}}(s)\right\}
\end{aligned}
$$

This procedure is derived from a test for periodically collapsing bubbles recently proposed by Phillips et al. (2011) as a further-development of cointegration-based tests for the existence of bubbles. This paper uses nominal daily as well as nominal monthly oil prices from 1986 to 2016 (West Texas Intermediate) to test for explosiveness in oil prices. ${ }^{5}$ The following section presents the empirical results.

\section{Results}

This section presents the results obtained from applying the test procedure outlined above to daily as well as monthly oil prices. Initially, the results for daily data are considered. The upper panel of Figure 2 displays oil prices as well as the sequence of p-values; p-values below $5 \%$ indicate rejection of the null hypothesis. As explained above, for periods in which the null of a

\footnotetext{
${ }^{4}$ Note that this is a standard unit root test except for the formulation of the alternative hypothesis. Rather than testing the null of a unit root against a stationary alternative, the alternative in this case is explosive.

${ }^{5}$ See Section 4 for a discussion of the differences between explosiveness and bubbles.
} 

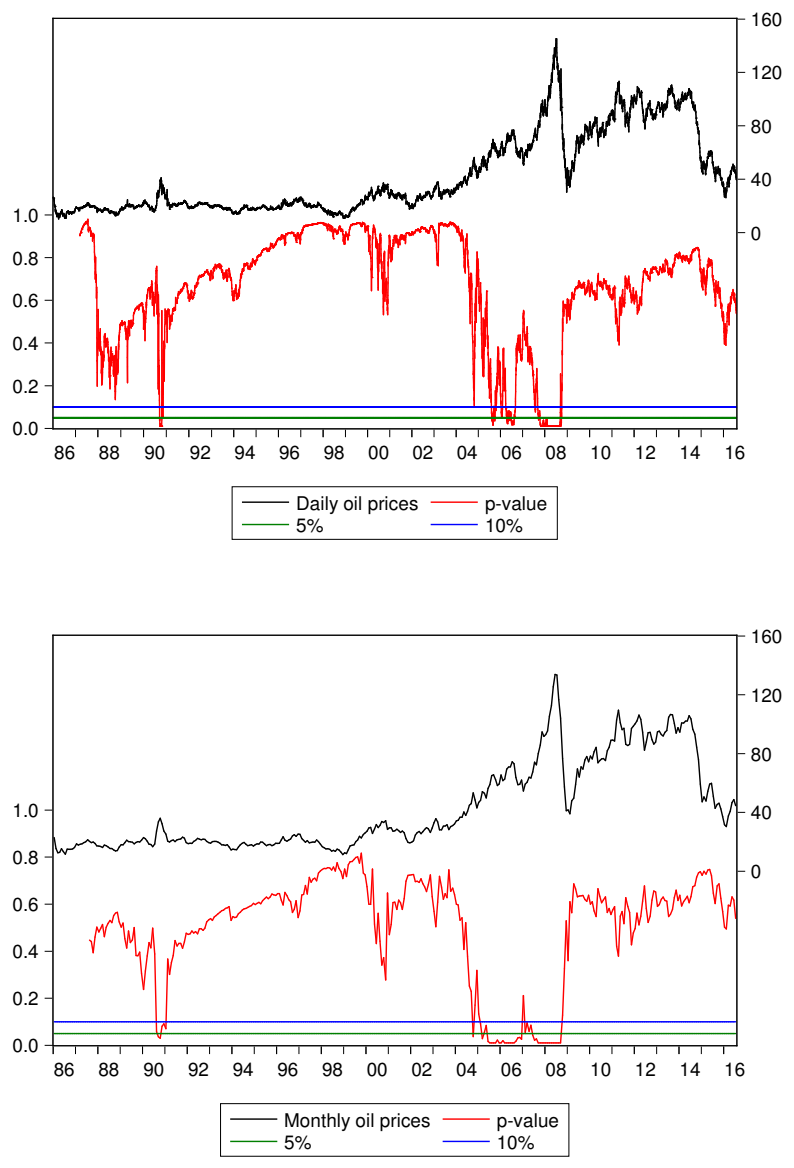

Figure 2: Explosiveness of daily and monthly oil prices 
unit root is rejected, oil prices are said to exhibit explosive behavior. ${ }^{6}$ This is found to be the case in the following periods: 1990/1991, 2005/2006 as well as 2007/2008. While the phase associated with Gulf War at the end of 1990 is of relative short duration, the two recent ones are about a year long. Analysis of monthly oil prices generally confirms these results (see Figure 2, lower panel). ${ }^{7}$

The finding of temporary phases of explosiveness adds to the vast literature on short-run as well as long-run oil price behavior. In the long run, oil prices are assumed to follow either deterministic (Slade, 1982a; Lee et al., 2006) or stochastic trends (Slade, 1988). ${ }^{8}$ On the short-run behavior front, a number of recent studies provide evidence of jumps in oil prices (Lee et al., 2010; Gronwald, 2012). Despite the concentrated effort that has been made to understand oil price behavior, temporary oil price increases like those observed in 1990/1991 and 2007/2008 are not well captured by any of the extant empirical approaches: the individual increases itself do not need to be very large, the overall increase period can exceed a few months and is followed by subsequent decreases. This paper's approach is certainly most comparable to the concept of stochastic trends: Had no evidence of explosive phases been found, the conclusion would have been that oil prices contain a unit root and, thus, follow a stochastic trend. ${ }^{9}$ Jump models,

\footnotetext{
${ }^{6}$ A consistent estimation of the precise origin and collapse date of the explosive behavior would require a significance level asymptotically approaching zero, see Phillips et al. (2011) and Phillips and Yu (2009). This paper, however, is more interested in the general behavioral pattern of oil prices. Research in that area is still ongoing and existing procedures are rather ad-hoc. Some alternative procedures have been applied as robustness check; the results are overall consistent with the results presented here. These results are available from the author upon request.

${ }^{7}$ Note that, at least in theory, the method applied in this paper would also allow one to capture "negative explosiveness" or "explosiveness in reverse". Figure 2 indicates that the p-values begin to decrease in 2014. However, they are still considerably larger than any conventional significance level. Thus, there would be insufficient evidence to conclude that "negative explosiveness" is present. In other words, the observed oil price declines are not large enough.

${ }^{8}$ It is important to note that this literature is concerned with resource and commodity price behavior in general. In addition to oil and petroleum prices, respectively, prices of other resources such as iron and silver are also analyzed.

${ }^{9}$ The application of a conventional unit root tests clearly indicates that oil prices contain a unit root. Detailed results are available from the author upon request.
} 
in addition, enjoy a considerable degree of popularity when it comes to modelling extreme price movements. However the feature that initially an increase consisting of a number of smaller steps is observed followed by the subsequent collapse cannot be captured very well by currently existing jump models. ${ }^{10}$ A considerable larger conceptual difference exists to the notion of deterministic trends. Lee et al. (2006) are proponents of this and their application of a two-break LM test is considered to reflect the "current state of knowledge concerning the empirical performance of nonrenewable resource prices" (Livernois, 2009). The unambiguous weakness of their approach is that the number of structural breaks is limited to two. In particular the feature of repeated switches between explosive and non-explosive behavior is not consistent with this rather inflexible concept; it seems obvious that oil prices are too dynamic to fit into this tight methodological corset. To summarise, this paper highlights a feature of oil prices which has so far not been considered in the empirical literature on oil price behavior: oil prices are temporarily explosive. The following section now discusses these results in a broader sense.

\section{Discussion}

In the aftermath of the 2008 oil price surge, a vast literature emerged that discusses its underlying causes. One main focus of that research is empiri-

\footnotetext{
${ }^{10}$ The following brief discussion explains this in more detail: The contributions by Lee et al (2010) as well as Gronwald (2012) are based on the jump model proposed by Chan and Maheu (2002). The key feature is that the variance equation, in addition to a standard GARCH component, also contains a jump component. This allows one to capture extreme price movements which exceed what would be anticipated by the GARCH model. The jumps are described by three parameters: a Poisson distributed jump intensity as well as a normally distributed jump size. It is important to note that the jumps in itself are independent from each other. The most recent applications allow for a time-varying jump intensity, but jump size and jump variance are time-invariant. This implies that these models do exhibit a certain degree of flexibility but do not seem be able to capture the empirical phenomenom of an initial increase in oil prices followed by a steep decrease. It should, furthermore, be noted that the main purpose of this paper is to put forward the conceptually new notion of temporary explosiveness and that there can very well be a fundamental explanation for the observed price movements. It is left for future research to investigate which type of model provides the better fit. Markov regime switching models in the tradition of Hamilton (1990) in general also seem to be useful candidates.
} 
cally testing the so-called Masters hypothesis, according to which long-only investment was a major driver of the 2007-2008 spike in commodity futures prices. This idea is also very popular with the public and there have already been calls for regulation of oil derivatives markets. However, no empirical support has been found for the Masters hypothesis. For example, Irwin and Sanders (2012) and Sanders and Irwin (2014) use extensive datasets on index fund investment in various commodity futures markets, and employ different statistical techniques.

While their focus is on the influence of index fund behavior on futures markets in specific, other papers address this issue more from the macro perspective. Kilian and Murphy (2013) specifically analyze the oil inventory channel. Within their four-variable structural VAR model (global crude oil production, a measure of global real activity, the real price of crude oil, and change in oil inventories above the ground), they identify four different types of shocks: an oil flow supply shock, an oil flow demand shock, a residual oil demand shock, and, most importantly, a speculative demand shock. This last shock is defined as a shock to the demand for "aboveground oil inventories arising from forward-looking behavior not otherwise captured by the model." The core finding that emerges from their paper is, as already mentioned, that the 2003-2008 oil price surge "was caused by unexpected increases in world oil consumption driven by the global business cycle."

Juvenal and Petrella (2014) extend Kilian and Murphy's (2013) analysis by using a dynamic factor model. They argue that small-scale VAR are not informationally sufficient to identify the shocks. In consequence, they use a set of factors capturing the bulk of aggregate information of a very large dataset consisting of macro-financial data as well as commodity prices. Their main finding is that global demand shocks account for the largest share of oil price fluctuations, but speculative shocks are the second most important driver. Their historical decomposition of oil prices for the period 2004-2010, furthermore, shows that speculative shocks contributed only about $15 \%$ to the oil price increase between 2004 and mid 2006. Between 2007 and 2008 the contribution of speculative shocks was found to be even smaller. 
Fattouh et al.'s (2013) survey of this literature concludes that "the comovements between spot and futures prices reflect common economic fundamentals rather than the financialization of oil futures markets." Hamilton (2009), in addition, argues that "a low price elasticity of demand and the failure of physical production to increase, rather than speculation per se, should be construed as the primary cause of the oil shock of 2007-08." Figure 3 displays data on global crude oil production and consumption. ${ }^{11}$ It is evident that for most of the time supply and demand are very close to each other, with the two lines often crossing each other. This applies in particular to the period prior to 2004. There are only two periods where one of the two lines seems to be persistently above the other: demand is higher than supply prior to 2008 and supply is higher than demand after 2014. These periods coincide with extreme oil price episodes: the record high witnessed in 2008 as well as the 2014 oil price collapse. An important role in this context play, as briefly mentioned above, low short-run demand and supply elasticities. Baumeister and Peersman (2013) even provide evidence of declining shortrun price elasticities of oil demand and of oil supply. Finally, Deaton and Laroque's (1992, 1995, and 1996) point to another essential issue: storage of a commodity cannot become negative. It is the interaction of all these fundamental factors that causes extreme crude oil price movements - captured in this paper using the concept of temporary explosiveness. The concept of explosiveness, in addition, allows one to capture commodity price behavior described by Deaton and Laroque using standard time series techniques.

These insights are insufficiently acknowledged by a number of contributions to the literature on speculative bubbles in crude oil prices. Garber (1990) emphatically stresses that "before economists relegate a speculative event to the inexplicable or bubble category, however, [they] must exhaust all reasonable economic explanations". In general, meaningful statements about the existence of bubbles can only be made if a measureable fundamental value exists. If a deviation of the observed price from this fundamental value becomes sufficiently large, one would conclude that a bubble is present. Cointegration based bubble tests suggest that no evidence of a bubble would

\footnotetext{
${ }^{11}$ Data source: Energy Information Administration.
} 


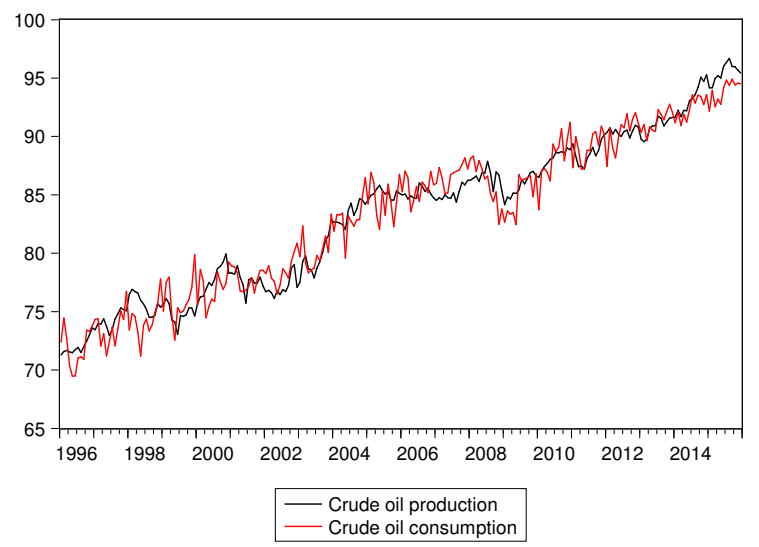

Figure 3: Crude oil production and consumption

be found if the observed price and the fundamental value are cointegrated. A necessary condition would be that the two time series are integrated of the same order. If however the price is more non-stationary than the fundamental value, this necessary condition would be violated and, thus, one would conclude that there is evidence of a bubble. As for the measurable fundamental value required for this analysis, in the context of stock markets, there is an obvious candidate: (expected future) dividends; see e.g. Philiips et al. (2011) as well as Diba and Grossmann (1988). On the oil price bubble front, however, it is at least debatable if this fundamental value is sufficiently careful defined. This literature is epitomised by studies such as Phillips and Yu (2011), Shi and Arora (2012) as well as Brooks et al.(2015). These papers find evidence of oil price bubbles; only the contribution by Caspi et al. (2015) is more cautious regarding the interpretation of their results. Phillips and Yu (2011) and Caspi et al (2015) merely normalize crude oil prices by crude oil supply - approximated by U.S. crude oil inventories. This is highly problematic in so far as this procedure assumes that U.S. inventories capture all relevant information on the fundamental value of crude oil prices. In addition, it imposes a restriction on the cointegration vector: it is assumed that this vector capturing the cointegration relationship between observed 
price and fundamental value is $(1,-1)$.

Shi and Arora (2012) and Brooks et al (2015) apply the present value model put forward by Pindyck (1993). This model is based on convenience yields which, however, is the valuation of future oil market conditions by the market itself rather than an "objective" fundamental value comparable to dividends. Brooks et al. (2015) are aware of potential problems and state that "the convenience yield could also be contaminated with a bubble itself". In order to check for the robustness of their results these authors construct a second measure for the fundamental value based on a set of macroeconomic variables. This proposal however is not unproblematic either as it entirely ignores oil market specific factors and is identical for a number of price series under consideration. In a nutshell, no reliable statement about the existence or non-existence of an oil price bubble can be made unless the fundamental values of oil prices are appropriately specified. However, the only thing we have learned - and it is one of the main contributions of this paper to emphasise this - is that crude oil prices exhibit temporary explosive behaviour and that there seem to be fundamental explanations for this peculiar behaviour.

\section{Conclusions}

Academic studies on crude oil are anything but scarce, but they do appear to be episodic. The oil crises of the 1970s sparked enormous efforts in investigating the macroeconomic consequences of oil price shocks. The emergence of various resource economic studies focusing on the scarcity of resources can also be linked to these incidents. A recent offshoot of this literature is motivated by increasing awareness of climate change and its consequences. And there seems to be an almost permanent interest in studying the statistical behavior of oil prices.

This paper puts forward the notion that the behavior of crude oil prices can be described as temporary explosive: The application of a unit root test based procedure yields evidence of temporary explosiveness in the following periods: 1990/1991, 2005/2006, and 2007/2008. This finding alone makes 
a contribution to the literature on the empirical behavior of oil prices epitomised by papers such as Pindyck (1999), Lee et al (2006), and Gronwald (2012). The crude oil price models used there are not able to capture this behavior. In addition, this procedure allows one to capture oil price behavior as described by Deaton and Laroque $(1992,1995,1996)$ using "traditional" time series techniques.

Having found evidence of this type of peculiar behavior, it is natural to try to shed light on the underlying causes. A thorough review of the literature reveals that these price movements, even though extreme, can very well have fundamental causes. The discussion in this paper shows that there is evidence of a change in the relationship of crude oil demand and supply fundamentals. The interaction of this with low price elasticities of crude oil supply and demand results in the observed extreme price movements. Making this clear is a second important contribution, for at least these two additional reasons: First, this seems to be insufficiently acknowledged by the literature on speculative oil price bubbles. The main weakness are the inappropriately defined fundamental values of oil prices utilized in these papers. In addition, there is a take-home point also for the general public. In many cases, sharply increasing prices result in calls for policy interventions and financial market regulations. The oil market is certainly not exempt from this. As these types of interventions can have undesirable effects this needs to be thought through extremely carefully.

In a nutshell, there is sufficient grounds for concluding that temporary phases of explosive oil prices cannot be considered rare events and that price movements of this type can very well have fundamental considerations. There is, however, an aspect of these movements that has attracted attention only very recently. Research on the micro level indicates that oil exploration investments rather than crude oil production responds to oil price increases - see Anderson et al. (2014) as well as Mauritzen (2016). In addition to this, research conducted by Miller and Zhang (1996) shows that oil field development decisions are affected even if oil price hikes are only temporary. Thus, current price turbulences will have an effect on future crude oil supply. Depending on which direction the global economy takes, it might be the case 
that extreme oil price periods will occur in the future as well. The global crude oil market seems to be undergoing a fundamental change.

\section{REFERENCES}

Anderson, S.T.., R. Kellogg and S.W. Salant (2014). "Hotelling under Pressure", NBER Working Paper Series Working Paper 20280

Baumeister, C. And G. Peersman (2013). "The Role of Time-Varying Price Elasticities in Accounting for Volatility Changes in the Crude Oil Market", Journal of Applied Econometrics 28: 1087-1109

Brooks, C., M. Prokopczuk and Y. Wu (2015). "Booms and busts in commodity markets: bubbles or fundamentals?", Journal of Futures Markets 35: 916-938

Caspi, I., N. Katzke And R. Gupta (2015). "Date Stamping Historical Periods of Oil Price Explosivity: 1876-2014", Energy Economics http:// dx.doi.org/10.1016/j.eneco.2015.03.029

Chan, W.H. And J.M. Maheu (2002). "Conditional Jump Dynamics in Stock Market Returns", Journal of Business Economics and Statistics 20(3): 377-389

Deaton, A. and G. Laroque (1992). "On the Behavior of Commodity Prices", Review of Economic Studies 59: 1-23

Deaton, A. And G. Laroque (1995). "Estimating a Nonlinear Rational Expectations Commodity Price Model with Unobservable State Variables", Journal of Applied Econometrics 10: S9-S40

Deaton, A. And G. Laroque (1996). "Competitive Storage and Commodity Price Dynamics", Journal of Political Economy 104: 896-923

Fattouh, B., L. Kilian And L. Mahadeva (2013). "The Role of Speculation in Oil Markets: What have we learned so far?", The Energy Journal 34(3): 7-33

Garber, P.M. (1990). "Famous First Bubbles", The Journal of Economic Perspectives $4(2): 35-54$

Gronwald, M. (2012). "A Characterization of Oil Price Behavior - Evidence from Jump Models", Energy Economics 34: 1310-1317

Hamilton, J.D. (1990). "Analysis of Time Series Subject to Changes in Regime", Journal of Econometrics 45(1-2): 39-70

Hamilton, J.D. (2009). "Causes and Consequences of the Oil Shock of 2007-08", Brookings Papers on Economic Activity 1: 215-261

Irwin, S.H. And D.R. SAnders (2012). "Testing the Masters Hypothesis in Commodity Futures Markets", Energy Economics 34: 256-269

Juvenal, L. And I.Petrella (2014). "Speculation in the Oil Market", Journal of Applied Econometrics DOI: 10.1002/jae 
Kilian, L. And D.P. Murphy (2013). "The Role of Inventories and Speculative Trading in the Global Market for Crude Oil", Journal of Applied Econometrics DOI: $10.1002 /$ jae.2322

Knittel, C.R. And R.S. Pindyck (2016). "The Simple Economics of Commodity Price Speculation", American Economic Journal: Macroeconomics 8(2)

Lee, J., J.A. List And M.C. Strazicich (2006). "Non-renewable Resource Prices: Deterministic or Stochastic Trends?", Journal of Environmental Economics and Management 51: 354-370

Lee, Y.H., H.S. Hu And J.S. Chiou (2010). "Jump Dynamics with Structural Breaks for Crude Oil Prices", Energy Economics 32: 343-350

Livernois, J. (2009). "On the Empirical Significance of the Hotelling Rule", Review of Environmental Economics and Policy 3(1): 22-41

Mauritzen, J. (2016). "The Effect of Oil Prices on Offshore Production: Evidence from the Norwegian Continental Shelf ", Oxford Bulletin of Economics and Statistics, http://dx.doi.org/10.1111/obes.12138

Miller, M. And L. Zhang (1996). "Oil Price Hikes and Development Triggers in Peace and War", The Economic Journal 106: 445-457

Phillips, P.C.B, AND Y. Wu (2009). "Limit Theory for Dating the Origination and Collapse of Mildly Explosive Periods in Time Series Data", unpublished manuscript, Singapore Management University

Phillips, P.C.B, Y. WU AND J. Yu (2011). "Explosive Behavior in the 1990s Nasdaq: When did Exuberance Escalate Asset Values", International Economic Review 52: 201-226

Phillips, P.C.B, AND J. Yu (2011). "Dating the Timeline of Financial Bubbles During the Subprime Crisis", Quantitative Economics 2: 455-491

PINDYCK, R.S. (1993). "The present value model of rational commodity pricing.", Technical report. National Bureau of Economic Research

PINDYCK, R.S. (1999). "The long-run Evolution of Energy Prices.", The Energy Journal, 20(2): 1-27

SANDERS, D.R. AND S.H. IRwin (2014). "Energy futures prices and commodity index investment: New evidence from firm-level position data", Energy Economics 46: S57-S68

Shi, S. And V. Arora (2012). "An application of models of speculative behaviour to oil prices", Economics Letters 115: 469-472

Slade, M.E. (1982A). "Trends in Natural-Resource Commodity Prices: An Analysis in the Time Domain", Journal of Environmental Economics and Management 9: 122-137 
Slade, M.E. (1982B). "Cycles in Natural-Resource Commodity Prices: An Analysis in the Frequency Domain", Journal of Environmental Economics and Management 9: 138-148

Slade, M.E. (1988). "Grade Selection under Uncertainty: Least Cost Last and Other Anomalies", Journal of Environmental Economics and Management 15: 189-205 